${ }^{1} \mathrm{H}$ NMR spectra are shown in Table IV.

(b) Preparation of Benzyl Ethers. A solution of the phenylsilyl alcohol $(1.83 \mathrm{mmol})$ in dry THF $(10 \mathrm{~mL})$ was added dropwise over $3 \mathrm{~min}$ to a solution of potassium tert-butoxide $(0.24 \mathrm{~g}, 2.20 \mathrm{mmol})$ in dry THF (40 $\mathrm{mL}$ ) under argon. The solution was then cooled to $0^{\circ} \mathrm{C}$ with an icewater bath, and benzyl bromide $(1.55 \mathrm{~g}, 9.2 \mathrm{mmol})$ was added dropwise over 2 min, causing the mixture to become cloudy. The mixture was stirred for $1 \mathrm{~h}$ at $0^{\circ} \mathrm{C}$, after which time the mixture was allowed to warm to room temperature. The solution was stirred at room temperature for $18 \mathrm{~h}$ and then was hydrolyzed by the addition of a saturated solution of aqueous ammonium chloride $(35 \mathrm{~mL})$. The clear yellow organic phase was separated from the aqueous phase, and the aqueous phase was extracted with $3 \times 80 \mathrm{~mL}$ portions of $\mathrm{Et}_{2} \mathrm{O}$. The combined organic phases were washed with $4 \times 80 \mathrm{~mL}$ portions of water, $2 \times 40 \mathrm{~mL}$ portions of $3 \mathrm{~N} \mathrm{HCl}, 80 \mathrm{~mL}$ of water, $2 \times 80 \mathrm{~mL}$ portions of a saturated solution of aqueous sodium carbonate, and $80 \mathrm{~mL}$ of brine and dried $\left(\mathrm{MgSO}_{4}\right)$ and the solvent was removed with a rotary evaporator, yielding a yellow oil. The excess benzyl bromide was removed by placing the oil under vacuum $(0.1 \mathrm{~mm})$ while heating the reaction vessel with a $70^{\circ} \mathrm{C}$ oil bath for $1 \mathrm{~h}$. Purification by flash chromatography on silica gel using a $7: 1$ mixture of $n$-hexane-methylene chloride afforded the pure (by ${ }^{1} \mathrm{H}$ NMR spectroscopy) ether in $\sim 50 \%$ yield based on the starting amount of alcohol. The 'H NMR spectra are shown in Table IV

(c) Protolytic Cleavage of the Silicon-Phenyl Bonds of the Benzyl Ethers. A solution of $\mathrm{HBF}_{4} \mathrm{OEt}_{2}(0.35 \mathrm{~g}$ of an $85 \%$ by weight solution in $\left.\mathrm{Et}_{2} \mathrm{O}, 1.83 \mathrm{mmol}\right)$ was added to a solution of the benzyl ether $(0.92$ $\mathrm{mmol})$ in dry chloroform $(10 \mathrm{~mL})$ that was cooled to $0{ }^{\circ} \mathrm{C}$ by an icewater bath. The mixture was stirred for $1 \mathrm{~h}$ at $0^{\circ} \mathrm{C}$, and then the solvent and other volatiles were removed by placing the system under vacuum $(0.1 \mathrm{mmHg})$ for $30 \mathrm{~min}$ at $0^{\circ} \mathrm{C}$, warming the reaction mixture to room temperature, and then pumping on it for an additional $5 \mathrm{~min}$. The remaining dark-brown oil was oxidatively cleaved as described for the hydrosilation products from terminally substituted allylic ethers, except that 5 equiv of potassium hydrogen carbonate were used instead of 4
The overall yields ranged from 60 to $70 \%$ of essentially pure (by ${ }^{1} \mathrm{H}$ NMR) 2-methyl-1,3-propanediol benzyl ether. The ${ }^{1} \mathrm{H}$ NMR spectrum is shown in Table IV.

Oxidative Cleavage of 1,1-Diphenylsilacyclopentanes. A solution of the 1,1-diphenylsilacyclopentane $(1.83 \mathrm{mmol})$, dry methylene chloride (10 $\mathrm{mL}$ ), and $\mathrm{HBF}_{4}\left(0.81 \mathrm{~g}\right.$ of an $85 \%$ by weight solution in $\mathrm{Et}_{2} \mathrm{O}, 3.48$ $\mathrm{mmol}$ ) was refluxed under argon for $18 \mathrm{~h}$. All of the volatiles were then removed under vacuum $\left(0.1 \mathrm{~mm}, 25^{\circ} \mathrm{C}, 30 \mathrm{~min}\right)$. The remaining dark-brown oil was then oxidatively cleaved as described for the hydrosilation products from terminally substituted allylic ethers, except that 5 equiv of potassium hydrogen carbonate were used instead of 4 . The product obtained was a 1:1 mixture of 2-methyl-1,4-butanediol and phenol. The yield of the desired diol was $45 \%$. More diol could be obtained by continuously extracting the combined aqueous phases with $\mathrm{Et}_{2} \mathrm{O}$ for $18 \mathrm{~h}$. The combined yield of the diol was $85 \%$. The phenol could be removed from the diol with a significant loss in yield by extracting an $\mathrm{Et}, \mathrm{O}$ solution of the diol and phenol with a $1 \mathrm{~N}$ sodium hydroxide in brine. The ${ }^{1} \mathrm{H}$ NMR spectrum of the di-Mosher's ester is shown in Table IV.

Preparation of Mosher's Esters. The Mosher's esters were prepared using literature procedures. ${ }^{13}$

Product Identification. The identities of most of the organic products were determined using the usual principles of NMR spectroscopy. Furthermore, the oxidative cleavage reaction verifies most of the assignments by acting as a degradative synthesis, converting the intramolecular hydrosilation products into known alcohols.

Acknowledgment. This work was supported by grants from the National Institutes of Health.

Supplementary Material Available: Listing of the ' $\mathrm{H}$ NMR data for 76 of the substrates, products, and derivatives (Table IV) (11 pages). Ordering information is given on any current masthead page.

\title{
Asymmetric Catalysis. Mechanism of Asymmetric Catalytic Intramolecular Hydrosilation
}

\author{
Steven H. Bergens, Pedro Noheda, John Whelan, and B. Bosnich* \\ Contribution from the Department of Chemistry, The University of Chicago, 5735 South Ellis \\ Avenue, Chicago, Illinois 60637. Received August 22, 1991
}

\begin{abstract}
The mechanism of asymmetric catalytic intramolecular hydrosilation using [Rh(diphosphine) ${ }^{+}$catalysts has been investigated by the use of specifically labeled deuterated substrates. It is concluded that oxidative addition of the silicon hydride bonds to the catalysts is rapid and reversible for most systems. Both 5-membered and 6-membered metallacycles are inferred to form rapidly and reversibly. These species are unproductive catalytic intermediates. It was inferred that $\beta$-hydride elimination is very rapid and is faster than chelate ring conformational interconversion. Hydrosilation proceeds by silyl olefin insertion. The turnover-limiting and enantioselective steps are believed to be the silyl olefin insertion. It is concluded that the major diastereomeric intermediate, the silyl metal olefin hydride, produces the major enantiomer of the product.
\end{abstract}

Speier's discovery that the homogeneous catalytic hydrosilation of olefins could be effected by the catalyst precursor $\mathrm{H}_{2}\left[\mathrm{PtCl}_{6}\right]^{1}$ led to numerous associated developments. These included homogeneous hydrosilation of acetylenes, ketones, imines, and diazines and the use of numerous other metal complexes as catalysts. $^{2}$ Although over 4000 papers have appeared on the subject, certain key features of the mechanism of hydrosilation remain in dispute. Further, no systematic mechanistic study of asymmetric catalytic hydrosilation has appeared. This paper attempts to address the central aspects of the mechanism of asymmetric ca-

(1) Speier, J. L.; Webster, J. A.; Barnes, G. H. J. Am. Chem. Soc. 1957, 79,974 .

(2) Lukevies, E.; Belyakova, Z. V.; Pomeraniseva, M. G.; Voronkov, M. G. Organomet. Chem. Rev. Seyferth, D., Davies, A. G., Fisher, E. O., Normant, J. F., Reutov, O. A., Eds. 1977, 5, 1 and references cited therein. talysis for the systems described in the previous paper in this issue. ${ }^{3}$

The generally accepted mechanism for olefin hydrosilation is depicted in Figure 1, the essential features of which were first postulated by Chalk and Harrod. ${ }^{4}$ This mechanism accounts for a number of observations associated with hydrosilation, notably the distribution of deuterium atoms during catalysis. Thus, the catalyzed reaction shown in eq 1 leads to almost statistical scrambling of the deuterium over all of the possible sites of the carbon atoms of the product and on the silicon. ${ }^{5}$ This result

$$
\mathrm{Cl}_{3} \mathrm{SiD}+=\left(\stackrel{\mathrm{H}_{2}\left[\mathrm{PtCl}_{6}\right]}{-\mathrm{Cl}_{3} \mathrm{Si}} \sim+\mathrm{Cl}_{3} \mathrm{SHH}+\mathrm{Cl}_{3} \mathrm{SiD}\right.
$$

(3) Bergens, S. H.; Noheda, P.; Whelan, J.; Bosnich, B. J. Am. Chem. Soc., preceding paper in this issue,

(4) Chalk, A. J.; Harrod, J. F. J. Am. Chem. Soc. 1965, 87, 16. 

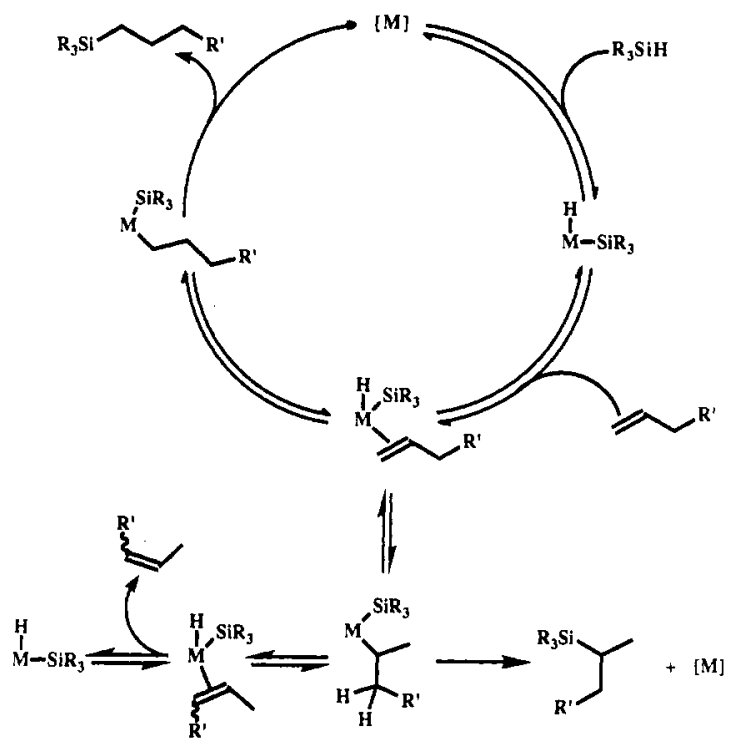

Figure 1.

supports the reversibility of the steps indicated in Figure 1 and implies that double bond migration can occur during catalysis. That this is so has been demonstrated in the catalytic reaction shown in eq 2.5 Double bond migration is generally much faster than hydrosilation. Thus, for example, when the mixture of [ $\operatorname{Ir}(\mathrm{COD}) \mathrm{Cl}]_{2}(\mathrm{COD}=$ cyclooctadiene $)$ and 1 equiv of $\mathrm{PPh}_{3}$ is allowed to catalyze the hydrosilation of 1-hexene with $\left(\mathrm{C}_{2} \mathrm{H}_{5}\right)_{3} \mathrm{SiH}$, almost complete conversion of the 1 -hexene to a mixture of internal olefins is observed after only $10 \%$ of hydrosilation. ${ }^{6}$

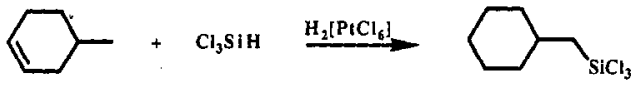

(2)

There are four other aspects known about the hydrosilation process. First, addition of the silyl group is preferred at terminal olefin positions over internal positions ${ }^{5,6}(\mathrm{eq} 2)$. Second, addition of the silicon and hydrogen atoms to the double bond is cis. Third, oxidative addition of the silyl hydride to the metal occurs with the retention of configuration at silicon. ${ }^{8}$ Fourth, the overall process of hydrosilation proceeds with retention of configuration at silicon. ${ }^{9}$ Hence, since oxidative addition proceeds with retention, the carbon-silicon bond-forming step must also proceed with retention.

For a variety of metal catalysts, ${ }^{10}$ the evidence overwhelmingly supports all of the steps in Figure 1 except for the final step, the reductive elimination of the silicon-carbon bond. Indeed, there is only one stoichiometric example of silyl-alkyl reductive elimination reported ${ }^{11}$ (eq 3 ). The mechanism of this reductive

$\left[\mathrm{Fe}(\mathrm{CO})_{4}\left(\mathrm{SiMe}_{3}\right)(\mathrm{R})\right] \longrightarrow \mathrm{RSiMe}_{3}+$ "Metal fragments" (3)

elimination is unknown, but formation of $\mathrm{RSiMe}_{3}(\mathrm{R}=$ methyl, benzyl) occurs slowly at $25^{\circ} \mathrm{C}$ in ether solvent. Although this result is consistent with the last step of the Chalk-Harrod mechanism (Figure 1), there are a number of observations that are not accommodated by this mechanism. For example, the catalysis of the reaction of 1-hexene with $\left(\mathrm{C}_{2} \mathrm{H}_{5}\right)_{3} \mathrm{SiH}$ generates

(5) Ryan, J. W.; Speier, J. L. J. Am. Chem. Soc. 1964, 86, 895.

(6) Oro, L. A.; Fernandez, M. J.; Esteruelas, M. A.; Jimenez, M. S. J. Mol. Catal. 1986, 37, 151.

(7) Selin, T. G.; West, R. J. Am. Chem. Soc. 1962, 84, 1863.

(8) Eaborn, C.; Hitchcock, P. B.; Tune, D. J.; Walton, D. R. M. J. Organome Chem. 1973, 54, Cl.

(9) Sommer, L. H; Michael, K, W. Fujimoto, H. J Am Chem Soc 1967, 89, 1519. Sommer, L. H.; Lyons, J. E.; Fujimoto, H. J. Am. Chem. Soc. 1969, 91, 7051 .

(10) Speier, J. L. Adv. Organomet. Chem. 1979, 17, 407.

(11) Blakeney, A. J.; Gladysz, J. A. Inorg. Chim. Acto. 1980, 53, L25, Brinkman, K. C.; Blakeney, A. J.; Krone-Schmidt, W.; Gladysz, J. A. Or ganometallics 1984, 3, 1325 .

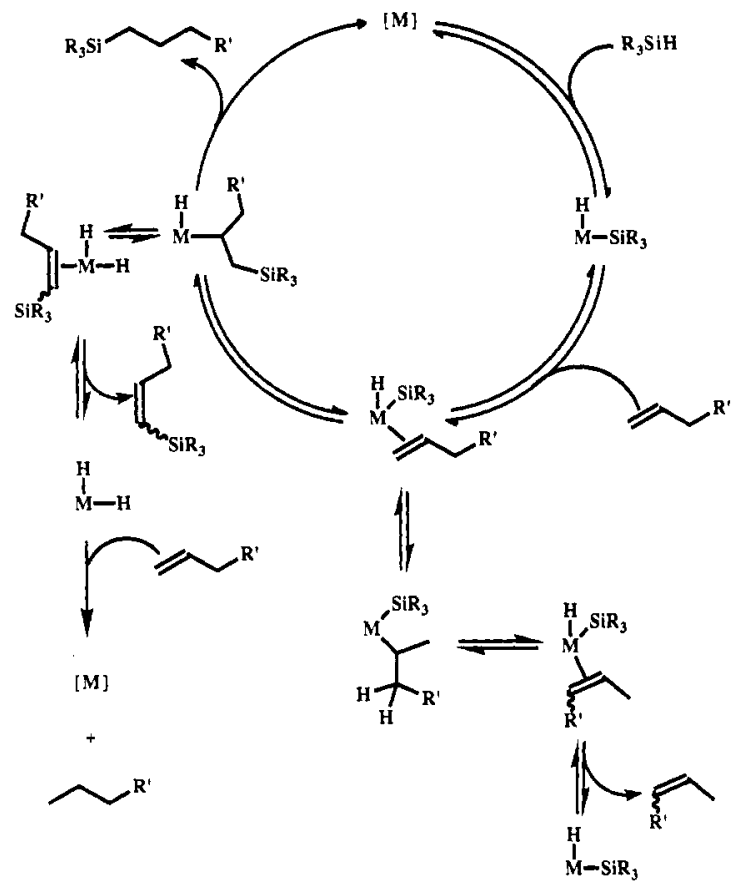

Figure 2.

almost $50 \%$ of vinylsilane $e^{6}$ (eq 4 ) in addition to the hydrosilation product and isomerized alkenes. There are many other examples of catalysts which generate varying amounts of vinylsilanes. The

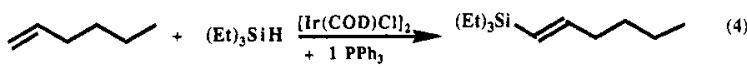

appearance of vinylsilanes is most easily accommodated by the silyl olefin insertion pathway depicted in Figure 2. The silyl olefin insertion mechanism can account for all of the other features of the Chalk-Harrod mechanism as well as offer a ready explanation for the appearance of vinylsilanes. The production of vinylsilanes implies that a dihydrido metal species is formed (Figure 2) and that this species could hydrogenate the olefin substrates. Indeed, it has been shown that the catalytic hydrosilation of 1 -hexene with $\left(\mathrm{CH}_{3}\right)\left(n-\mathrm{C}_{10} \mathrm{H}_{12}\right)_{2} \mathrm{SiH}$ and the catalyst $\left[\mathrm{Rh}\left(\mathrm{PPh}_{3}\right)_{3} \mathrm{Cl}\right]$ leads to the production of 1 equiv of hexane for every equivalent of vinylsilane produced. ${ }^{12}$

Direct observation of silyl olefin insertion was provided by the stoichiometric experiment outlined in eq $5 .{ }^{13}$ The last step in this sequence proceeds thermally at $25^{\circ} \mathrm{C}$ to give the insertion product. Irradiation of the insertion product 2 led to the formation of $65 \%$ of the vinylsilane ( $\beta$-hydride elimination) and $15 \%$ of the olefin complex 1 , the result of $\beta$-silyl elimination. This important experiment shows that, for this system, olefin insertion into the metal-silicon bond is a relatively facile and reversible process.

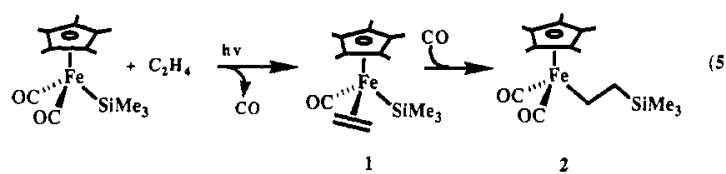

This brief and selective survey of the mechanistic observations suggests that either of the two mechanisms, silicon carbon reductive elimination or silyl olefin insertion, could occur for a particular catalytic system. The demonstration that a key step is possible for a particular stoichiometric reaction does not necessarily imply that it will occur in catalysis, since the outcome will depend on the relative rates of the steps in question.

(12) Onopchenko, A.; Sabourin, E. T.; Beach, D. L. J. Org. Chem. 1984, 49,3389 3366 . 
<smiles>[Y][Y]([H])([H])OCC=CC</smiles><smiles>[R][Y]1([R])[15NH]C(C([2H])[2H])CO1</smiles><smiles>[R]C1C(CC=CC)CO[Y]1([R])[H]</smiles>

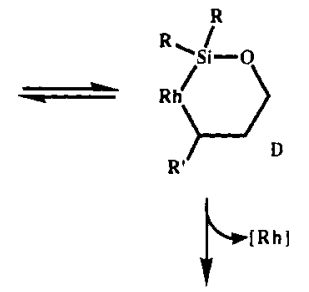<smiles>[R]C1C=C([Y9]([H])([H])[H])COS1([R])([R])([R])C=C</smiles>

F<smiles>[C+]1C[Pb]P[Pb]1</smiles>

Figure 3.

\section{Mechanistic Questions}

The preceding discussion allows us to address specific questions about the mechanism of the catalytic asymmetric intramolecular hydrosilation reaction described in the previous paper (eq 6). The<smiles>[Y3][SiH2]OCC([R9])[R3]</smiles><smiles>[Y]C1CO[Si]([B])([B])C1[B]</smiles>

(6)

principal questions are as follows. First, is oxidative addition of the silyl-hydrogen bond rapid and reversible $(A \rightleftarrows B$, Figure 3$)$ ? Second, does a 5-membered metallacycle (C) form and is this process reversible $(B \rightleftharpoons C)$ ? Third, does a 6 -membered metallacycle (D) form, and does it lead to product $(D \rightarrow G)$ or is the process reversible $(B \rightleftarrows D)$ ? Fourth, does olefin insertion into the metal-silicon bond occur to give $E$, does it lead to product, and is this process reversible $(B \rightleftarrows E)$ ? Fifth, if $E$ is formed, does $\beta$-hydride elimination occur to give $F$ and is this process reversible $(\mathrm{E} \rightleftharpoons \mathrm{F})$ ? Sixth, which is the turnover-limiting step of the catalytic cycle? Seventh, which is the enantioselective step?

Since we were unable to detect any intermediates during catalysis, we have inferred answers to these questions by observing the fate of deuterium atoms in specifically labeled substrates. The initial experiments involved the use of the deuterated substrate $3^{14}$ and catalysts of the type [Rh(diphosphine)(acetone) $\left.{ }_{2}\right]^{+}$in acetone solutions at $25^{\circ} \mathrm{C}$. The diphosphines were, $(S, S)$-chiraphos, diphos, odppb, and $(S)$-binap. Catalyst loadings were usually $1 \mathrm{~mol} \%$, and the concentrations of substrates were 0.13 M. Each of these catalysts reveals different aspects of the catalytic mechanism with the substrate 3 .<smiles></smiles><smiles>CC(c1ccccc1)[C@H](C)c1ccccc1</smiles>

2. Oxidative Addition, Reductive Elimination, and 5-Membered Chelate Ring Formation

Using the $(S, S)$-chiraphos catalyst and substrate 3 , we find that $55 \%$ cyclization occurs in $5 \mathrm{~min}$. The remaining substrate has an almost statistical distribution of deuterium atoms at the silicon

(14) Corey, J. Y.; West, R. J. Am. Chem. Soc. 1963, 85, 2430.

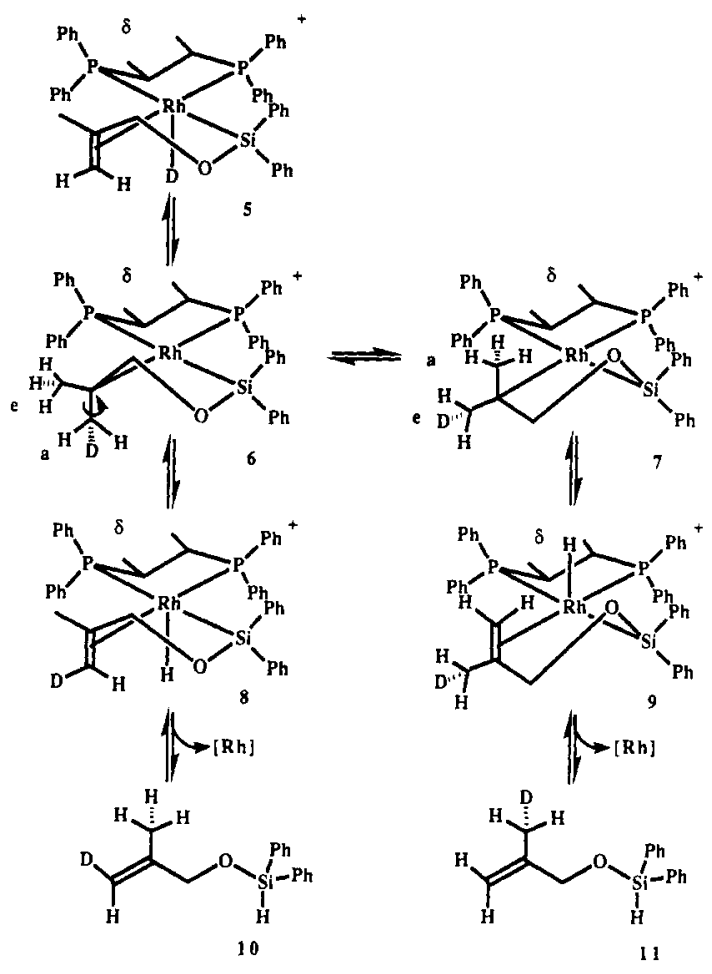

Figure 4

and an equal distribution at the $E$ and $Z$ positions of the olefin. The cyclized product 4 after $5 \mathrm{~min}$, and at the end of catysis, contains a statistical distribution of deuterium atoms at the positions shown in 4. Moreover, EI mass spectrometry indicates that there is no cross over of labels between molecules. No deuterium was found at the methylene group bonded to the oxygen atom in 4 .

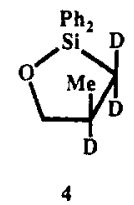

These results are consistent with rapid and reversible oxidative addition of the silyl hydride ( $A \rightleftarrows B$, Figure 3 ) and also of rapid reversible formation of the 5 -membered metallacycle $(B \rightleftarrows C)$. Since both $E$ and $Z$ deuterium isomers of the substrate are observed, the rotation of the requisite methyl group of the 5-membered metallacycle intermediate is rapid, allowing any of the hydrogen atoms to be abstracted. This two-step reversibility is much faster than the hydrosilation process and hence leads to complete scrambling of the label among the possible positions of the substrate and also of the possible positions in the product.

There is, however, one surprising feature associated with the catalysis of 3: no deuterium is found in the methyl group of the equilibrated substrate nor in the methyl group of the product 4. The significance of this observation is illustrated in Figure 4. We assume that olefin insertion into the metal-hydride bond is more probable when the metal-hydride bond is parallel to the bound olefin carbon-carbon bond. Similar arguments should apply to the microscopic reverse, $\beta$-hydride elimination.

Figure 4 shows the preferred conformation of $(S, S)$-chiraphos ${ }^{15}$ and various conformations of the oxidatively added substrate. The putative intermediate 5 has a substrate conformation which aligns the olefin for insertion into the metal-deuterium bond to give 6 . If the substrate conformation of 6 remains the same as in 5 and if the axially (a) disposed methyl group can rotate before $\beta$-hydride elimination occurs, then by the sequence $6 \rightarrow 8 \rightarrow 10$ the $E$ - and $Z$-deuterio olefin isomers of $\mathbf{1 0}$ will be formed, depending on which 
methyl hydrogen atom is abstracted. If, however, the substrate conformer of 6 flips to the conformer depicted in 7, the undeuterated methyl group will move from an equatorial (e) position in $\mathbf{6}$ to the axial position in 7. This axially disposed methyl group in 7 is aligned for $\beta$-elimination, and by the sequence $7 \rightarrow 9 \rightarrow$ 11 deuterium would appear in the methyl group of the substrate 11. Experiment shows that $\mathbf{1 1}$ is not formed. There are two possible explanations for this result. First, since 6 and 7 are diastereomers, they are energetically distinct. Thus, it could be that the diastereomeric intermediate 6 is much preferred over 7 , and if the rates of $\beta$-elimination for 6 and 7 are similar, the $7 \rightarrow$ $9 \rightarrow 11$ sequence is not observed. We can envision the origins of the diastereomeric discriminations as arising from the interactions of the silyl phenyl groups and the two methyl groups of the substrate with the phenyl groups of the chiral diphosphine. The second possibility is that $\beta$-elimination is much faster than ring flipping so that after olefin hydride insertion occurs, $\beta$ elimination always occurs from the newly formed methyl group. This issue is most directly resolved by the use of the achiral diphosphine odppb, but before we address this question, we describe some revealing results observed with the diphos catalyst.

Catalysis of substrate 3 with the diphos catalyst is much faster than with the $(S, S)$-chiraphos analogue. After $1.25 \mathrm{~min}, 75 \%$ substrate conversion had occurred and, although no deuterium scrambling in the remaining substrate was observed, almost statistical scrambling of deuterium was observed in the indicated positions of the product 4 . This is a significant result since it implies that olefin hydride insertion and $\beta$-hydride elimination associated with the 5 -membered metallacycle and production of product are much faster processes than silicon hydride reductive elimination $(B \rightarrow A)$ in this case. The effects that distinguish the chiraphos from the diphos catalysts must be exceedingly subtle, but both results demonstrate the high rates of $B \rightleftharpoons C$ equilibration.

As with the chiraphos catalyst, no deuterium is observed in the methyl group of the product 4 with the diphos analogue. It is possible to contrive a similar argument to that illustrated in Figure 4 for the diphos catalyst in terms of conformational locking of the 5-membered metallacycle and the diphos, but the matter is resolved by the results obtained from the achiral odppb catalyst. Cyclization of 3 with the odppb catalyst also produces the product 4 with no deuteration of the methyl group. We therefore conclude that olefin hydride insertion and $\beta$-elimination are much faster than ring conformational flipping, that is, only the path $5 \rightleftharpoons 6$ $\rightleftarrows 8$ occurs (but not $6 \rightleftarrows 7$ ) (Figure 4 ) during deuterium scrambling. Since ring flipping is expected to be fast, this is a remarkable observation since it indicates that $\beta$-hydride elimination in this system is an exceedingly fast process.

\section{Silyl Olefin Insertion versus Metallacycle Reductive Elimination}

Using the odppb-derived catalyst and substrate $3,70 \%$ conversion occurs after $3 \mathrm{~min}$. No exchange of the Si-D bond is observed in the remaining substrate and, as for the case of the diphos catalyst, scrambling is observed in the product but the deuterium distribution is different from that observed previously. This is shown in 12. The assignments were made by NOE

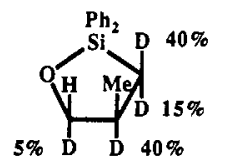

12

experiments. The significant differences from previous results are the appearance of deuterium at the oxygen-bound methylene group in the position trans to the methyl group and the unequal distribution of deuterium population at the other methylene group. Although these experiments do not allow for a quantitative analysis, the general implications are significant. The simplest interpretation of the deuterium distributions in $\mathbf{1 2}$ is that they arise from the consequences of olefin insertion into the metal-silyl bond. This is shown in Figure 5.

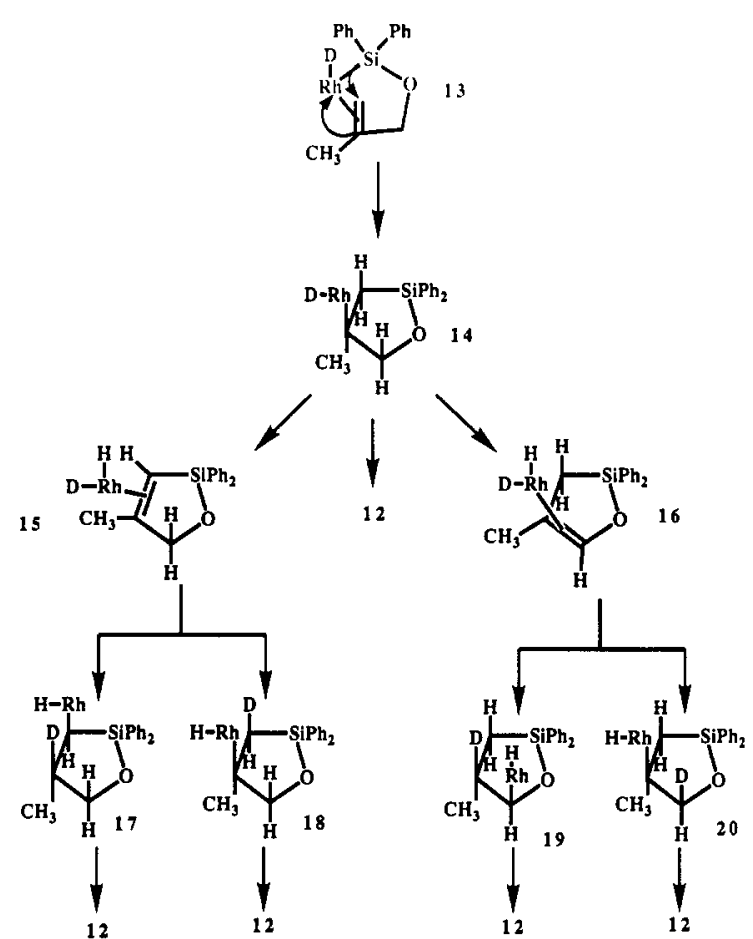

Figure 5.

Olefin insertion into the metal-silyl bond in intermediate $\mathbf{1 3}$ leads to intermediate 14. Because of the geometrical constraints imposed on the ring in 14, only methylene protons trans to the methyl group are capable of $\beta$-hydride elimination. Elimination of one or other of these trans-disposed protons leads, respectively, to the two dihydrido olefin intermediates, 15 and 16. In each of 15 and 16, olefin insertion into the metal-deuteride bond leads to the intermediates $17, \mathbf{1 8}, \mathbf{1 9}$, and $\mathbf{2 0}$, depending on the double bond isomer, 15 or 16, and which end of the olefin inserts. These final intermediates then reductively eliminate to the product 12 . The fact that deuteration is stereoselective, appearing only at the trans-disposed $O$-methylene hydrogen atom 12 and causing uneven distribution about the other methylene group, indicates that the olefin face coordination in $\mathbf{1 5}$ and $\mathbf{1 6}$ does not switch by olefin dissociation. Were olefin dissociation to occur, we would expect to find deuterium in both the cis and trans positions in the $O$ methylene group and possibly the appearance of the dissociated olefin in solution accompanied by hydrogenation of the substrate. Olefin was not observed and neither was any evidence for hydrogenation found. Although we are not in a position to discuss the quantitative aspects of the deuterium distribution, the fact that the deuterium population of the trans-disposed methylene hydrogen atoms of $\mathbf{1 2}$ does not appear to be statistical suggests that the rates of $\beta$-hydride elimination $(14 \rightarrow 15$ or 16$)$ and that of alkane hydride reductive elimination to produce 12 are competitive. The fact that neither the chiraphos nor diphos catalyst shows evidence of stereoselective deuteration of the trans-hydrogen atoms suggests that reductive elimination to produce 4 is a much faster process than $\beta$-hydride elimination provided, of course, that in these cases olefin silyl insertion is involved.

The $(S)$-binap catalyst shows a pattern similar to that observed for the odppb catalyst. After $2.5 \mathrm{~min}, 35 \%$ of the substrate is converted and about $15 \%$ of the substrate contains $\mathrm{Si}-\mathrm{H}$ bonds, suggesting that, unlike the case of the odppb catalyst, the rate of substrate reductive elimination is competitive with the hydrosilation rate. The distribution of deuterium in the product derived from the $(S)$-binap catalyst is similar to that observed for odppb. Thus, we find 5\% deuterium trans to the methyl group at the $O$-methylene position, $22 \%$ deuterium in the trans position of the $\mathrm{Si}$ methylene group, and $28 \%$ deuterium in the cis position of the same group. The rest of the deuterium (45\%) is attached to the carbon atom bearing the methyl group. This distribution is similar to that observed for the odppb catalyst, and we offer 


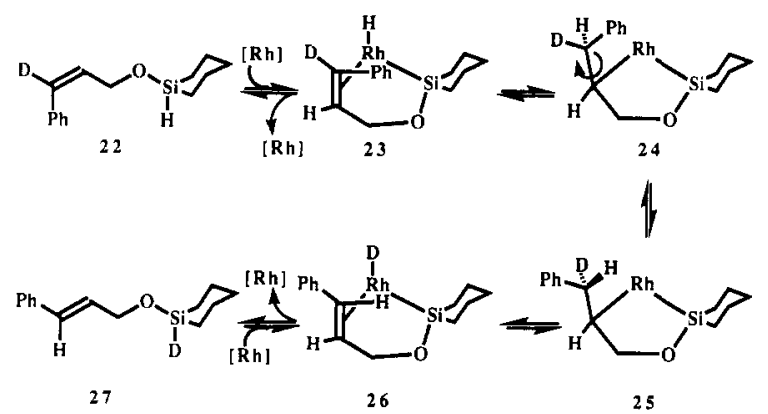

Figure 6.

a totally analogous interpretation (Figures 4 and 5).

We should note that in both the odppb and $(S)$-binap catalytic reactions, but not in the other two, there is about $1 \%$ deuterium incorporation at the ortho positions of the phenyl groups attached to the silicon of the product. Presumably this reflects the presence of orthometalation during catalysis, suggesting that the silicon phenyl groups are not chemically passive although we have no evidence to suggest that orthometalation has a significant effect on the course of catalysis.

There remains one intriguing feature of the deuterium distribution in all of these transformations which relates to the absence of deuterium in the methyl group of the product. We have addressed this issue in the context of the equilibration depicted in Figure 4, but the olefin silyl insertion mechanism shown in Figure 5 suggests that the methyl group in intermediates 14,18 , and 20 could $\beta$-hydride eliminate. Such a $\beta$-elimination could lead to deuterium incorporation in the methyl group of the product. None was detected within the accuracy of the measurements $(\sim 2 \%)$. We have no satisfactory explanation for this result, except to note that the driving force for forming endocyclic double bonds in the present system is probably greater than for forming the exocyclic double bond and that this may be reflected in the relative rates of $\beta$-hydride elimination.

\section{Enantioselective Hydrosilation}

As shown in the preceding paper, both substrates $\mathbf{2 1}$ and $\mathbf{2 2}$ give $\sim 96 \%$ ee in acetone solution at $25^{\circ} \mathrm{C}$ with the $(S)$-binap catalyst. The $(R)$-diol is produced.

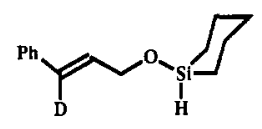

21<smiles>[2H]/C(=C/CO[SiH]1CCCC1)c1ccccc1</smiles>

22
Under the conditions described previously, $10 \%$ of the cis substrate 22 is cyclized by $(S)$-binap after $1.5 \mathrm{~min}$. The remaining substrate consists of 5\% of the starting cis species 22 and the rest $(85 \%)$ is the trans olefin isomer 27 (Figure 6). Moreover, the remaining trans substrate has all of its deuterium attached to the silicon atom; none remains at its original location, namely, the terminal position of the olefin. After about $7 \mathrm{~min}, 33 \%$ cyclization occurs and the remaining $67 \%$ of the substrate is the all-trans isomer with the deuterium solely located at silicon. The implications of these results are illustrated in Figure 6.

Oxidative addition of the cis substrate 22 generates 23, which undergoes olefin hydride insertion to give 24 . This latter intermediate (24) allows for rotation of the benzylic group so that the benzylic deuterium atom (rather than the hydrogen atom as in 24 ) is aligned for $\beta$-elimination. Upon $\beta$-elimination of 25 , the trans olefin 26 is formed which, upon reductive elimination, gives the trans substrate with the deuterium bound to the silicon atom. The complete stereoselectivity of the benzylic hydrogen atom abstraction is remarkable. Although many kinetic factors may be involved, one of the factors that contributes to the rapid formation of the trans isomer may be a strong sterically induced preference for the disposition of the phenyl group in the orientation shown in 25. Since equilibrium between the cis and trans substrate isomers appears to have been established before complete catalytic cyclization, the sequences depicted in Figure 6 are rapid and

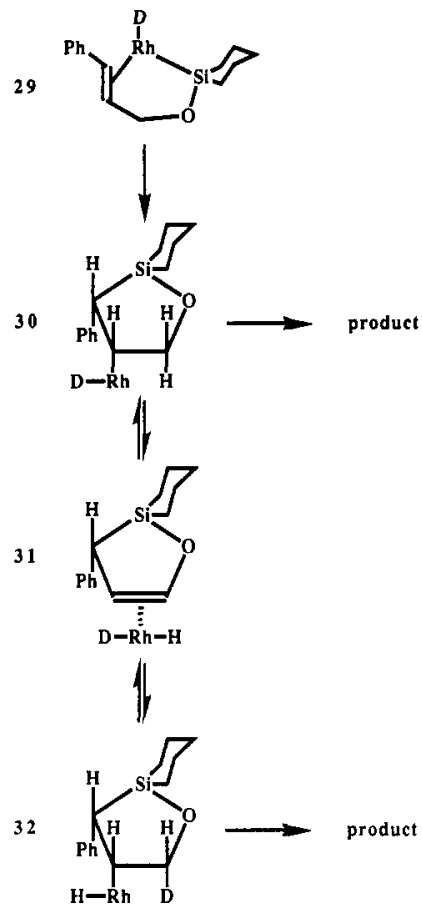

Figure 7.

reversible on the time scale of catalytic cyclization. Moreover, since both the cis and trans substrates give the same (almost quantitative) ee, the conclusion that, with the cis substrate, all of the hydrosilation proceeds via the trans substrate seems inescapable. This conclusion is confirmed by the deuterium distribution in the product (28). The absence of deuterium at the carbon atom bearing the phenyl group in the product establishes that all of the cyclization proceeds via the trans substrate (27). The position of the deuterium atoms in 28 were established by relay $\mathrm{NOE}$ experiments. We note that $\mathrm{Si}-\mathrm{D}$ addition to the double bond is cis as expected.

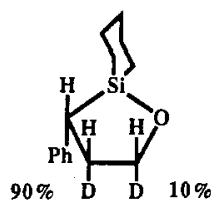

28

The presence of $10 \%$ specific deuterium incorporation in the $O$-methylene group cis to the phenyl group in $\mathbf{2 8}$ is most simply explained by the process shown in Figure 7 . The sequence in Figure 7 involves olefin silyl insertion to form 30, which can reductively eliminate to give the product with the deuterium on the central methylene group. The deuterium and the phenyl group will be cis-disposed. Alternatively, 30 may $\beta$-hydride eliminate to give the hydrido-deuterio-rhodium-olefin intermediate 31 , which has the rhodium and phenyl groups disposed cis. Insertion of the olefin into the deuterio-rhodium bond will deliver the deuterium cis to the rhodium (32). Reductive elimination from 32 gives the product with the deuterium cis to the phenyl group as observed. The selectivity of this latter deuteration indicates that the olefin in 31 does not exchange to allow the rhodium to bind to the other olefin face. The alternative explanation, namely that the rhodium complex is completely face selective after olefin exchange, seems unlikely since the olefin coordination mode depicted in $\mathbf{3 1}$ has what would seem to be the less favored form because of the steric hindrance engendered by the cis dispositions of the rhodium and the phenyl group. We note that selective deuteration was observed for the achiral odppb catalyst, where no prochiral olefin face selectivity is possible.

The stereoselective deuteration of the $O$-methylene group indicates that at least $10 \%$ of the intramolecular hydrosilation 


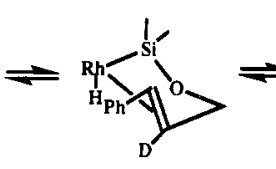

36
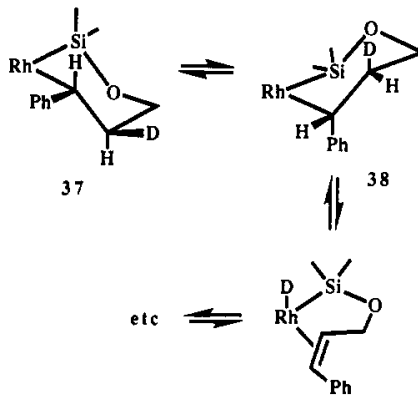

39
Figure 8.

involves the olefin silyl insertion path. This must be a lower limit because, as is evident in Figure 7, some acts of $\beta$-hydride elimination-olefin hydride insertion will be unobservable because of hydride and deuteride scrambling during the mechanism. Since, however, nearly quantitative ee is observed for the trans-cinnamyl substrates, it seems highly improbable that these high ee's could be obtained by a dual mechanism where some of the catalysis proceeds by the Chalk-Harrod mechanism and some by the olefin silyl insertion mechanism. We conclude, therefore, that the intramolecular hydrosilation with the present catalysts proceeds by the olefin silyl insertion mechanism.

Hydrosilation of the trans substrate 21 with the $(S)$-binap catalyst leads to no scrambling of the deuterium; all of the deuterium remains at the benzylic position. This result is wholly consistent with the stereoselective abstraction of the benzylic proton of the 5-membered metallacycle in the process illustrated in Figure 6. Were the deuterium abstracted in this intermediate, the cis isomers $\mathbf{2 2}$ or $\mathbf{2 3}$ would form, but the results on the substrate $\mathbf{2 2}$ indicate that the rate of formation of 27 , the trans substrate, is much greater than the rate of production of the cis isomer 22.

\section{6-Membered Metallacycle Formation}

In order to investigate the possibility of the $\mathrm{B} \rightleftarrows \mathrm{D}$ equilibrium (Figure 3), the two specifically deuterated substrates 33 and 34 were investigated in catalysis. Using the binap catalyst for 33 and the chiraphos catalyst for 34 , no scrambling of the deuterium is observed in the product or in the substrate during reaction. The deuterium is disposed trans to the phenyl group in the product of 33, and all of the deuterium is in the position indicated in 35 , as expected from cis addition.

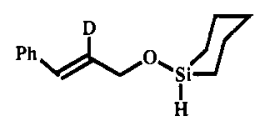

33

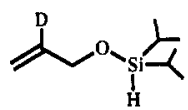

34

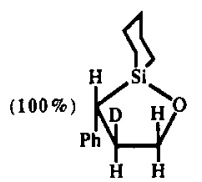

35

This lack of deuterium mobility, we believe, arises from the more rapid rate of $\beta$-hydride elimination from the 6 -membered ring than that of ring flipping. This is illustrated in Figure 8. Olefin insertion into the metal-hydride bond of 36 leads to 37 where, in the chair 6-membered chelate ring, the phenyl group and the deuterium are equatorially disposed. The hydrogen atom resulting from insertion is axially disposed and, by microscopic reversibility, it is this axial hydrogen atom that can $\beta$-eliminate to give back 36. In order to $\beta$-eliminate the deuterium, the ring has to flip to give 38 where now the deuterium is axial and so too is the phenyl group. Elimination of deuterium from 38 will give 39 where the olefin is now cis. By processes discussed previously, 39 could lead to (unobserved) deuterium scrambling. It could be argued that the lack of scrambling in the catalysis of $\mathbf{3 3}$ is due to the necessity of an axial phenyl group in $\mathbf{3 8}$ or the formation of the thermodynamically unfavorable cis olefin 39 . This argument is difficult to sustain since $\mathbf{3 4}$ is devoid of these impediments and yet shows no deuterium scrambling. Since olefin hydride insertion is a rapid and reversible process in the formation of 5-membered chelate rings, it seems improbable that the formation of 6-membered chelate rings is not a rapid reversible process also. We therefore conclude that the absence of deuterium scrambling in the catalysis of $\mathbf{3 3}$ and 34 is because $\beta$-elimination from the 6 -membered ring is faster than ring flipping. This conclusion is reminiscent of the one we drew for the stereoselective methyl group deuteration of substrate 3 .

Finally, it might be possible to account for some of the deuterium scrambling observed in some of these systems by a reversible double bond migration mechanism involving a $\pi$-allylic intermediate. An inspection of the stereoselective nature of the deuterium scrambling in the various systems described here suggests that reversible double bond migration is improbable, but perhaps the most direct evidence is provided by the binap catalysis of substrate 40 . The products of this catalysis are the species 41 , 42, and 43 in the indicated percentages. Species 41 is the normal

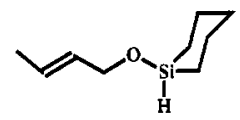

40

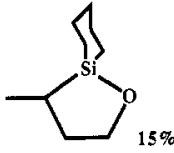

4

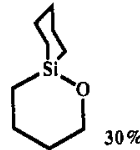

42

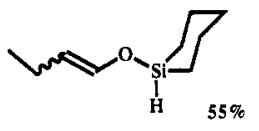

43 hydrosilation product; species $\mathbf{4 2}$ must arise from prior double bond migration of $\mathbf{4 0}$, probably via the 6 -membered metallacycle. The fate of the enol ether $\mathbf{4 3}$ is the most telling evidence, for we find that once all of the substrate 40 is consumed, the ratio of $\mathbf{4 1 , 4 2}$, and the enol ether $\mathbf{4 3}$ does not change, indicating that the enol ether $\mathbf{4 3}$ is not transformed by the catalyst to the substrate $\mathbf{4 0}$. Over time, the enol ether $\mathbf{4 3}$ decomposes to unidentified products.

\section{Turnover-Limiting and Enantioselective Steps}

The preceding data provides persuasive evidence that the mechanism of asymmetric catalytic intramolecular hydrosilation proceeds by the olefin silyl insertion mechanism. The following discussion will focus on the two substrates, 21 and 22, which give high ee's, but the conclusions we draw probably apply to related substrates with these catalysts. We have shown that $\mathrm{Si}-\mathrm{H}$ oxidative addition is rapid and reversible $(A \rightleftarrows B$, Figure 3 ) and that the catalytically unproductive 5 -membered metallacycle formation is also rapid and reversible ( $\mathrm{B} \rightleftarrows \mathrm{C}$ ). Hence, the turnover-limiting step is either the silyl olefin insertion $(B \rightarrow E)$ or the alkyl hydride reductive elimination $(E \rightarrow G)$. Our studies provide no direct information as to the relative rates of these steps, but there is indirect evidence to suggest that the turnover-limiting step is the silyl olefin insertion. We have established that $\beta$-hydride elimination is an exceedingly fast process relative to the overall rate of catalysis. We have shown that the $\beta$-hydride elimination involving intermediates $E$ and $F$ leads to incomplete scrambling of deuterium, suggesting that the rates of reductive elimination ( $E$ $\rightarrow G$ ) to form product and $\beta$-hydride elimination and hydride olefin insertion $(E \rightleftharpoons F)$ are competitive. If $\beta$-hydride elimination is exceedingly fast on the time scale of catalysis, then so too is the hydride alkyl reductive elimination step $(E \rightarrow G)$. Provided we can use $\beta$-hydride elimination as a clock for relative rates and that silyl olefin insertion is slower than $\beta$-hydride elimination, then the turnover-limiting step of catalysis is the silyl olefin insertion.

The enantioselective step of an asymmetric catalytic reaction is the first irreversible step involving diastereomeric transition states. Given the preceding evidence, the enantioselective step is either the silyl olefin insertion or the hydride alkyl reductive elimination. The present experiments provide no direct evidence for the reversibility or otherwise of silyl olefin insertion, although 


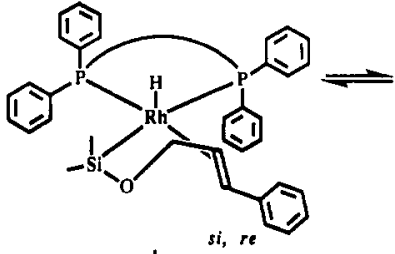

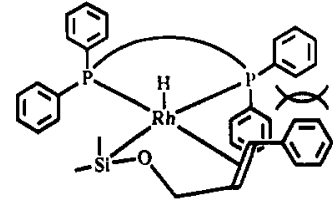

re, si<smiles>CCCCCCCCC</smiles>

Figure 9.

the hydride alkyl reductive elimination is irreversible. It seems likely that the silyl olefin insertion is irreversible in the present systems. The cyclic intermediate $\mathrm{E}$ is short lived, and the presence of the silicon in the cyclic system is likely to form a highly strained transition state for $\beta$-silyl elimination. It is on this basis that we are inclined to postulate that the silyl olefin insertion is irreversible and is therefore the enantioselective step.

\section{Origins of the Enantioselectivity}

By an inspection of the mechanism in Figure 3 and from the knowledge that the catalysis proceeds by the silyl olefin insertion path, it is clear that the olefin face selection in intermediate B is related to the enantioselectivity. The two possible diastereomeric intermediates using $(S)$-binap and substrate $\mathbf{2 1}$ are shown in Figure 9.

We assume that the intermediate has an approximate square pyramidal geometry, although the steric arguments which follow are not critically dependent on whether the structure is distorted. Molecular models show that the diastereomer with the bound re olefin face is much more stable than the one bound si olefin face because, in the latter, there is very strong interaction between the olefin phenyl group and the equatorially disposed phenyl group of $(S)$-binap. The preferred enantiomer of the product is of $R$ absolute configuration, which indicates that the diastereomer with the bound re olefin face is the more reactive. Thus, if the steric arguments are correct, the prevailing enantiomer of the product originates from the more stable diastereomer.

\section{Conclusions}

The preceding results allow us to draw the following conclusions about the mechanism of asymmetric catalytic intramolecular hydrosilation with the present catalysts. First, silicon hydrogen oxidative addition is rapid and reversible. Second, the catalytically unproductive 5-membered metallacycle is formed rapidly and reversibly. Third, $\beta$-hydride elimination is faster than conformational flipping. Fourth, the catalytically unproductive 6membered metallacycle is probably also formed, but it rapidly $\beta$-hydride eliminates. Fifth, catalysis proceeds by silyl olefin insertion. Sixth, silyl olefin insertion is the turnover-limiting step and is also probably the enantioselective step. Finally, we note that these conclusions apply to the present systems and that other catalysts and substrates may operate by a different mechanism.

\section{Experimental Section}

${ }^{1} \mathrm{H}$ NMR spectra were measured on General Electric (GE) GN 500 , GN 300, and QE 300 Fourier transform spectrometers operated at 500.1, 300.1 , and $300.2 \mathrm{MHz}$, respectively. ${ }^{2} \mathrm{H}$ NMR spectra were measured on GE GN 500 and GN 300 Fourier transform spectrometers operated at 76.8 and $46.1 \mathrm{MHz}$, respectively. ${ }^{31} \mathrm{P}$ NMR spectra were measured on a GE GN 300 Fourier transform spectrometer operating at 121.7 MHz. ${ }^{1} \mathrm{H}$ and ${ }^{2} \mathrm{H}$ NMR chemical shifts were measured relative to a TMS external reference. ${ }^{31} \mathrm{P}$ NMR chemical shifts were measured relative to an $85 \% \mathrm{H}_{3} \mathrm{PO}_{4}$ external reference. The solvents, $\mathrm{Et}_{2} \mathrm{O}$ (Li$\left.\mathrm{AlH}_{4}\right), \mathrm{C}_{6} \mathrm{H}_{6}\left(\mathrm{CaH}_{2}\right)$, hexanes $\left(\mathrm{CaH}_{2}\right)$, pentane (3- $\AA$ molecular sieves), $\mathrm{CH}_{2} \mathrm{Cl}_{2}\left(\mathrm{CaH}_{2}\right)$, THF $\left(\mathrm{K}, \mathrm{Ph}_{2} \mathrm{CO}\right)$, and $\left(\mathrm{CD}_{3}\right)_{2} \mathrm{CO}(3-\AA$ molecular sieves), were distilled from drying agents under either nitrogen or argon gas. Wherever possible, all starting materials were distilled under argon or recrystallized before use. Diphenyldichlorosilane, lithium aluminum deuteride, chlorotriphenylmethane, propargyl alcohol, $\mathrm{PhC} \equiv \mathrm{CCO}_{2} \mathrm{Et}$, $20 \%$ by weight $\mathrm{DCl}$ in $\mathrm{D}_{2} \mathrm{O}, \mathrm{D}_{2} \mathrm{O}$, dicyclopentadienyltitanium dichloride, and isobutylmagnesium chloride $\left(2.0 \mathrm{M}\right.$ solution in $\left.\mathrm{Et}_{2} \mathrm{O}\right)$ were supplied by Aldrich. The $\mathrm{PhC} \equiv \mathrm{CCH}_{2} \mathrm{OH}$ was supplied by Lancaster and the 1,2-bis(diphenylphosphino)benzene by Strem. The diisopropylchlorosilane, ${ }^{3}$ 1-chlorosilacyclohexane, ${ }^{3}\left[\mathrm{Rh}((S)\right.$-binap)(NBD) $] \mathrm{ClO}_{4}{ }^{16}[\mathrm{Rh}$ $((S, S)$-chiraphos $)]_{2}\left(\mathrm{ClO}_{4}\right)_{2},{ }^{3}$ and $[\mathrm{Rh}(\mathrm{dppe})]_{2}\left(\mathrm{ClO}_{4}\right)_{2}{ }^{17}$ were prepared by published procedures.

Preparation of Diphenyldideuteriosilane. A solution of $\mathrm{Ph}_{2} \mathrm{SiCl}_{2}(32.9$ $\mathrm{g}, 129.9 \mathrm{mmol})$ in dry $\mathrm{Et}_{2} \mathrm{O}(20 \mathrm{~mL})$ was added dropwise over $15 \mathrm{~min}$ to a mixture of $\mathrm{LiAlD}_{4}(3 \mathrm{~g}, 71.6 \mathrm{mmol})$ in $\mathrm{Et}_{2} \mathrm{O}(80 \mathrm{~mL})$ under argon. The heat liberated by the reaction was sufficient to maintain a gentle reflux of the $\mathrm{Et}_{2} \mathrm{O}$ during the addition. The mixture was then refluxed for $1 \mathrm{~h}$, cooled to $0^{\circ} \mathrm{C}$, quenched by the careful addition of $3 \mathrm{~mL}$ of $\mathrm{H}_{2} \mathrm{O}$ and $3 \mathrm{~mL}$ of a $15 \%$ solution of $\mathrm{NaOH}$ in $\mathrm{H}_{2} \mathrm{O}$, warmed to room temperature, and treated with $9 \mathrm{~mL}$ of $\mathrm{H}_{2} \mathrm{O}$. This resulted in a colorless solution with a gray, gelatinous solid. The $\mathrm{Et}, \mathrm{O}$ layer was decanted off the solid phase. The solid was extracted with $3 \times 80 \mathrm{~mL}$ portions of $\mathrm{Et}_{2} \mathrm{O}$. Each portion of $\mathrm{Et}_{2} \mathrm{O}$ was refluxed over the solid for $5 \mathrm{~min}$ before it was decanted off. The combined $\mathrm{Et}_{2} \mathrm{O}$ layers were dried $\left(\mathrm{MgSO}_{4}\right)$ and then reduced down to $28.3 \mathrm{~g}$ of a colorless oil with a white precipitate using a rotary evaporator. The mixture was treated with pentane $(100$ $\mathrm{mL}$ ) and stirred for $20 \mathrm{~min}$, causing more precipitation. Suction filtration through Celite followed by removal of the solvent using a rotary evaporator yielded $21.9 \mathrm{~g}$ of a clear, colorless oil. Distillation yielded diphenyldideuteriosilane $\left(19.14 \mathrm{~g}, 79 \%\right.$ yield, bp $\left.104-104.5^{\circ} \mathrm{C}(7 \mathrm{~mm})\right)$. ${ }^{1} \mathrm{H} \mathrm{NMR}\left(\mathrm{CDCl}_{3}, 500 \mathrm{MHz}\right)$ spectroscopy showed the residual $\mathrm{Si}-\mathrm{H}$ to be $<0.1 \%$.

Preparation of Diphenyldeuteriochlorosilane. A mixture of diphenyldideuteriosilane $(10.00 \mathrm{~g}, 53.7 \mathrm{mmol})$, benzene $(100 \mathrm{~mL})$, and chlorotriphenylmethane $(14.98 \mathrm{~g}, 53.7 \mathrm{mmol}$ ) was refluxed under argon for $48 \mathrm{~h}$. The golden-yellow solution was concentrated down to a deepyellow oil by distilling off the solvent under atmospheric pressure. The oil partially solidified upon cooling to room temperature. The mixture was cooled at $0^{\circ} \mathrm{C}$ with rapid stirring for $10 \mathrm{~min}$ and then filtered through dry Celite. The yellow crystals were quickly washed with $3 x$ $20 \mathrm{~mL}$ portions of near-freezing benzene. The filtrate was distilled, yielding a clear, colorless oil $\left(9.81 \mathrm{~g}\right.$, bp $\left.81-95^{\circ} \mathrm{C},(0.1 \mathrm{~mm})\right)$. The material was redistilled to yield $6.45 \mathrm{~g}\left(55 \%\right.$ yield, bp $82-85^{\circ} \mathrm{C}(0.1$ $\mathrm{mm})$ ) of an oil consisting of diphenylchlorodeuteriosilane (96\%) and diphenyldideuteriosilane (4\%) (ratios determined by ${ }^{2} \mathrm{H}$ NMR). ${ }^{1} \mathrm{H}$ NMR spectroscopy showed the residual $\mathrm{Si}-\mathrm{H}$ to be $<0.1 \%$. The material was used without further purification.

Preparation of 2-Propen-1-ol- ${ }^{2} \mathrm{H}$. This is an adaptation of a literature procedure. ${ }^{18}$ A solution of 2-propyn-1-ol $(3.85 \mathrm{~g}, 68.7 \mathrm{mmol})$ in dry $\mathrm{Et}_{2} \mathrm{O}(50 \mathrm{~mL})$ was added dropwise over 15 min to a mixture of $\mathrm{LiAlD}_{4}(4.40 \mathrm{~g}, 105.0 \mathrm{mmol})$ in $\mathrm{Et}_{2} \mathrm{O}(200 \mathrm{~mL})$ under argon. The heat liberated by the reaction was sufficient to maintain a gentle reflux of the $\mathrm{Et}_{2} \mathrm{O}$ during the addition. The resulting colorless solution with a white precipitate was refluxed for $18 \mathrm{~h}$ and then cooled to $0^{\circ} \mathrm{C}$. The mixture was quenched by the careful addition of $\mathrm{H}_{2} \mathrm{O}(4.4 \mathrm{~mL})$ followed by a $15 \%$ $\mathrm{NaOH}$ solution in $\mathrm{H}_{2} \mathrm{O}(4.4 \mathrm{~mL})$. The solution was then warmed to room temperature, and more $\mathrm{H}_{2} \mathrm{O}(13.2 \mathrm{~mL})$ was added dropwise to give a colorless solution with a granular, white precipitate. $\mathrm{The} \mathrm{Et}_{2} \mathrm{O}$ was refluxed for $30 \mathrm{~min}$ and then decanted off. The solid was extracted twice with two $150-\mathrm{mL}$ portions of $\mathrm{Et}_{2} \mathrm{O}$. Both times the $\mathrm{Et}_{2} \mathrm{O}$ was refluxed on the solid for 30 min before it was decanted off. The combined $\mathrm{Et}_{2} \mathrm{O}$ layers were dried $\left(\mathrm{MgSO}_{4}\right)$ and then reduced down to a light-brown oil by distillation of the $\mathrm{Et}_{2} \mathrm{O}$ through a vacuum-jacketed Vigreux column under argon. The material was distilled through a spinning-band column, yielding $1.8 \mathrm{~g}$ (bp $85-98^{\circ} \mathrm{C}$ ) of a clear, colorless oil consisting of deuterio-2-propen-1-ol, propanol-2,2-2 $\mathrm{H}_{2}$ (10.2\%), and $\mathrm{Et}_{2} \mathrm{O}(2.4 \%)$. It was determined by ${ }^{1} \mathrm{H}$ NMR spectroscopy that the deuterio-2-propen-1-ol was $92 \%$ deuterated at the 2-position. ${ }^{2} \mathrm{H}$ NMR spectroscopy revealed $8.5 \%$ deuteration at the 3-trans-position as well. It was not determined whether the 3-position deuteration occurred in the same molecules as the 2-position deuteration since the mechanistic interpretations were the same for either case provided that the initial ratios were known.

Preparation of trans-3-Phenyl-2-propen-1-ol-2 ${ }^{2} \mathrm{H}$. The compound was prepared with the same procedure used to prepare 2-propen-1-ol-2. ${ }^{2} \mathrm{H}$ to yield a clear, colorless oil (bp $108-112^{\circ} \mathrm{C}(7 \mathrm{~mm})$ ) consisting of deuterio-3-phenyl-2-propen-1-ol (99\%) and dideuterio-3-phenylpropan-

(16) Miyashita, A.; Takaya, H.; Souchi, T.; Noyori, R. Tetrahedron 1984, 40,1245 .

(17) Fairlie, D. P.; Bosnich, B. Organometallics 1988, 7, 936.

(18) Kwart, H.; Miles, W. H.; Horgan, A. G.; Kwart, L. D. J. Am. Chem. Soc. 1981, 103, 1757. Kwart, H.; George, T. J. J. Am. Chem. Soc. 1977, 99 , 5214. 
1-ol by 'H NMR. The deuterio-3-phenyl-2-propen-1-ol consisted of $98 \%$ trans-3-phenyl-2-propen-1-ol-2-2 $\mathrm{H}$ and $2 \%$ cis-3-phenyl-2-propen-1-ol${ }^{2-}{ }^{2} H$ both by ${ }^{1} \mathrm{H}$ and ${ }^{2} \mathrm{H}$ NMR spectroscopy. The total percent deuteration was 100 .

Preparation of trans-3-Phenyl-2-propen-1-ol-3- ${ }^{2} \mathrm{H}$. A solution of ethyl phenylpropionate $(9.80 \mathrm{~g}, 56.3 \mathrm{mmol})$ in dry $\mathrm{Et}_{2} \mathrm{O}(40 \mathrm{~mL})$ was added dropwise over $35 \mathrm{~min}$ to a mixture of $\mathrm{LiAlH}_{4}(2.16 \mathrm{~g}, 56.9 \mathrm{mmol})$ in $\mathrm{Et}_{2} \mathrm{O}$ $(150 \mathrm{~mL})$ under argon. The heat liberated by the reaction was sufficient to maintain a gentle reflux of the $\mathrm{Et}_{2} \mathrm{O}$ during the addition. The resulting colorless solution with a light-gray precipitate was refluxed for $15 \mathrm{~min}$, cooled to $0{ }^{\circ} \mathrm{C}$, and then, while vigorous stirring was maintained, carefully treated with $D_{2} \mathrm{O}(2.0 \mathrm{~g}, 100.0 \mathrm{mmol})$ over $10 \mathrm{~min}$ followed by $20 \%$ by weight $\mathrm{DCl}$ in a $\mathrm{D}_{2} \mathrm{O}$ solution $(1.0 \mathrm{~g}, 5.3 \mathrm{mmol}$ of $\mathrm{DCl}$ ) over $5 \mathrm{~min}$. The mixture was refluxed for $10 \mathrm{~min}$ and then hydrolyzed by the careful addition with vigorous stirring of $\mathrm{H}_{2} \mathrm{O}(9.8 \mathrm{~g})$ at $0^{\circ} \mathrm{C}$, a $15 \%$ by weight $\mathrm{NaOH}$ solution in $\mathrm{H}_{2} \mathrm{O}(9.8 \mathrm{~g})$ at $25^{\circ} \mathrm{C}$, and $\mathrm{H}_{2} \mathrm{O}(20 \mathrm{~mL})$ at $25^{\circ} \mathrm{C}$ A colorless solution with a granular, white precipitate was produced. The mixture was vacuum filtered through a glass sinter, and the precipitate was washed three times with warm $\mathrm{Et}_{2} \mathrm{O}(60 \mathrm{~mL}$ each). The combined $\mathrm{Et}_{2} \mathrm{O}$ layers were dried $\left(\mathrm{MgSO}_{4}\right)$ and filtered, and the solvent was removed to yield $7.5 \mathrm{~g}$ of a pale yellow oil. Distillation yielded the product as a clear, colorless oil $\left(5.80 \mathrm{~g}, 76 \%\right.$ yield, bp $\left.115-117^{\circ} \mathrm{C}(7 \mathrm{~mm})\right) .{ }^{1} \mathrm{H}$ NMR spectroscopy showed that the product consisted of trans-3phenyl-2-propen-1-ol-3-2 $H(95.3 \%)$ and the remainder was the cis isomer. The total percent deuteration was 96.4 .

Preparation of cis-3-Phenyl-2-propen-1-ol-3-2 H. This is an adaptation of a literature procedure. ${ }^{19}$ Solid dicyclopentadienyltitanium dichloride $(0.91 \mathrm{~g}, 3.7 \mathrm{mmol})$ was quickly added to a solution of isobutylmagnesium chloride $(10.33 \mathrm{~g}, 88.4 \mathrm{mmol})$ in $\mathrm{Et}_{2} \mathrm{O}(94 \mathrm{~mL})$ while the reaction vesse was flushed with argon. The dark black-blue solution was stirred at 25 ${ }^{\circ} \mathrm{C}$ for $5 \mathrm{~min}$ and then cooled to $0{ }^{\circ} \mathrm{C}$. 3-Phenyl-2-propyn-1-ol $(4.7 \mathrm{~g}$, $35.6 \mathrm{mmol}$ ) was added dropwise over $4 \mathrm{~min}$. Rapid gas evolution occurred as each drop of the alcohol was added to the reaction solution. The resulting dark brown-black solution with a black-brown precipitate was stirred at $0^{\circ} \mathrm{C}$ for $1 \mathrm{~h}$, warmed to $25^{\circ} \mathrm{C}$, and then stirred for an additional $18 \mathrm{~h}$. Slow gas evolution occurred during this time, and a black solid encrusted the walls of the flask. The solid was broken up, and stirring was continued for an additional hour. The reaction was hydrolyzed by the careful addition of $\mathrm{D}_{2} \mathrm{O}(3.2 \mathrm{~g}, 160 \mathrm{mmol})$ followed by $\mathrm{H}_{2} \mathrm{O}$ $(10 \mathrm{~mL})$ and then $1 \mathrm{~N} \mathrm{HCl}(25 \mathrm{~mL})$. The dark-brown organic phase was separated from the dark-brown aqueous phase, and then the aqueous phase was extracted with $4 \times 30 \mathrm{~mL}$ portions of $\mathrm{Et}_{2} \mathrm{O}$. The combined $\mathrm{Et}_{2} \mathrm{O}$ layers were washed with $\mathrm{H}_{2} \mathrm{O}(30 \mathrm{~mL})$, twice with a saturated aqueous solution of $\mathrm{NaHCO}_{3}(30 \mathrm{~mL}$ each), and brine $(30 \mathrm{~mL})$ and then was dried with $\mathrm{MgSO}_{4}$ for $18 \mathrm{~h}$. The $\mathrm{MgSO}_{4}$ absorbed all of the darkcolored material, leaving a pale-yellow $\mathrm{Et}_{2} \mathrm{O}$ layer. The solvent was removed to yield a golden-yellow oil $(3.4 \mathrm{~g})$. The composition was determined by ' $\mathrm{H}$ NMR to be 3-phenyl-2-propyn-1-ol $(9.2 \%)$, 3-phenylpropan-1-ol-2,3,3-2 $\mathrm{H}_{3}$ (12.3\%), trans-3-phenyl-2-propen-1-ol-3.2 ${ }^{2} \mathrm{H}$ (11.4\%), and cis-3-phenyl-2-propen-1-0l-3. ${ }^{2} H(67.1 \%)$. Flash column chromatography (hexanes $\mathrm{CH}_{2} \mathrm{Cl}_{2}, 1: 3$ ) afforded $2.45 \mathrm{~g}$ of a clear, colorless oil composed of 3-phenylpropan-1-ol-2,3,3-2 $\mathrm{H}_{3}(13.7 \%$ ), trans-3phenyl-2-propen-1-ol-3-2 $\mathrm{H}$ (25.5\%), and cis-3-phenyl-2-propen-1-ol-3- ${ }^{2} \mathrm{H}$ (60.8\%) (composition determined by ${ }^{1} \mathrm{H}$ NMR spectroscopy). Distillation afforded a clear, colorless oil $\left(1.16 \mathrm{~g}\right.$, bp $\left.99-107^{\circ} \mathrm{C}(7 \mathrm{~mm})\right)$, the composition of which was 3-phenylpropan-1-ol-2,3,3-2 $\mathrm{H}_{3}(16.3 \%)$, trans-3-phenyl-2-propen-1-ol-3-2 $H$ (13.7\%, 95\% deuterated), and cis-3phenyl-2-propen-1-0l-3-2 $H$ (70\%, 95\% deuterated). The compound was used without further purification.

Preparation of [Rh(odppb)(NBD)]ClO ${ }_{4}$ 1,2-Bis(diphenylphosphino)benzene $(0.289 \mathrm{~g}, 0.65 \mathrm{mmol})$ was added as a solid to a -78

(19) Sato, F.; Ishikawa, H.; Watanabe, H.; Miyake, T.; Sato, M. J. Chem. Soc., Chem. Commun. 1981, 718.
${ }^{\circ} \mathrm{C}$ solution of $\left[\mathrm{Rh}(\mathrm{NBD})_{2}\right] \mathrm{ClO}_{4}(0.250 \mathrm{~g}, 0.65 \mathrm{mmol})$ in $\mathrm{CH}_{2} \mathrm{Cl}_{2}(12$ $\mathrm{mL}$ ) while the reaction vessel was flushed with argon. Stirring was continued at $-78^{\circ} \mathrm{C}$ for $20 \mathrm{~min}$ while the diphosphine dissolved slowly with concomitant formation of a pale-orange precipitate. The mixture was then warmed to $25^{\circ} \mathrm{C}$ and stirred for $2 \mathrm{~h}$. After addition of hexane $(10 \mathrm{~mL})$, the product was isolated as an orange-yellow powder by vacuum filtration through a fine glass sinter in air. The product was washed twice with hexanes ( $5 \mathrm{~mL}$ each) and dried under a stream of warm air. It was recrystallized by dissolving the solid in boiling $\mathrm{CH}_{2} \mathrm{Cl}_{2}(150 \mathrm{~mL})$ and precipitating by the addition of hot THF $(50 \mathrm{~mL})$. The mixture was allowed to stand for $3 \mathrm{~h}$ at room temperature, and the product was isolated as orange platelets on a glass sinter, washed quickly with $\mathrm{CH}_{2} \mathrm{Cl}_{2}$ $(1 \mathrm{~mL})$ followed by pentane $(2 \times 1 \mathrm{~mL}$ portions), and dried under a stream of warm air. Yield: $0.237 \mathrm{~g}, 49 \%$. ' $\mathrm{H}$ NMR $(300 \mathrm{MHz}$, $\left.\mathrm{CD}_{2} \mathrm{Cl}_{2}\right): \delta 7.7-7.3(\mathrm{~m}, 24 \mathrm{H}$, aromatic), 5.35 (br s, $4 \mathrm{H}$, vinylic), 4.16 (br s, $2 \mathrm{H}$, methine), 1.84 (br s, $2 \mathrm{H}, \mathrm{CH}_{2}$ ). ${ }^{31} \mathrm{P}$ NMR $(121.7 \mathrm{MHz}$ $\left.\mathrm{CD}_{2} \mathrm{Cl}_{2}\right): \delta 59.9\left(\mathrm{~d}, J_{\mathrm{Rh}-\mathrm{P}}=159.4 \mathrm{~Hz}\right)$.

Hydrogenation of $\left[\mathbf{R h}\left(\right.\right.$ odppb)(NBD) ClO $_{4}$. Hydrogen gas was bubbled through a solution of [Rh(odppb)(NBD)] $\mathrm{ClO}_{4}(1.53 \mathrm{mg}, 2.1 \mathrm{mmol})$ in acetone $(0.6 \mathrm{~mL})$ for $4 \mathrm{~min}$ while the reaction mixture was vigorously agitated. A ${ }^{\prime} H$ NMR spectrum showed that complete reduction of the norbornadiene ligand to generate free norbornane had occurred and that no rhodium(III)-hydride complexes had formed. The ${ }^{31}$ P NMR spectrum contained only one species with equivalent phosphorus atoms. ${ }^{31 \mathrm{P}}$ NMR $\left(121.7 \mathrm{MHz},\left(\mathrm{CD}_{3}\right)_{2} \mathrm{CO}\right): \delta 78.3\left(\mathrm{~d}, J_{\mathrm{Rh}-\mathrm{P}}=195.3 \mathrm{~Hz}\right)$. All of these observations are entirely consistent with the formation of $[R h-$ (odppb)(acetone) ${ }_{2} \mathrm{ClO}_{4}$

Preparation of Silyl Ethers. The silyl ethers were prepared using the same procedure as in the previous paper. ${ }^{3}$ The chemical yields ranged from 30 to $75 \%$, depending on the purity of the starting material. The chemical composition and isotopic distribution of the silyl ethers were the same as those of the corresponding allyl alcohols. The ${ }^{1} \mathrm{H}$ NMR spectra of the nondeuterated analogues are given in the previous paper. ${ }^{3}$

Catalytic Runs. Typically, $[\mathrm{Rh} \text { (diphosphine) }]_{2}\left(\mathrm{ClO}_{4}\right)_{2}\left(7.80 \times 10^{-4}\right.$ $\mathrm{mmol})$ was dissolved in acetone- $d_{6}(0.6 \mathrm{~mL})$ under argon. The substrate $\left(7.80 \times 10^{-2} \mathrm{mmol}, 100\right.$ equiv) was then added via syringe. The reactions were monitored by NMR spectroscopy. The [Rh(diphosphine)(NBD) $]^{+}$ complexes were hydrogenated to the $\left[\mathrm{Rh}\right.$ (diphosphine)(acetone), ${ }^{+}$ species prior to the introduction of the substrate as follows: the [Rh(diphosphine)(NBD) $]^{+}$complex was suspended in the solvent, and $\mathrm{H}_{2}$ was bubbled through the solvent for $2 \mathrm{~min}$. The gas flow was stopped, and the NMR tube was shaken for $2 \mathrm{~min}$. This procedure was repeated twice to give clear solutions of the disolvento complexes. The solutions were then purged with argon, the substrate was added, and the catalysis was monitored by NMR spectroscopy. In all cases the impurities present in the substrate were found either not to react or to react independently with the catalyst. Thus, for example, the $13.7 \%$ of $\mathbf{2 1}$ present in $\mathbf{2 2}$ reacted with the catalyst to yield the corresponding amount of the silacyclopentyl ether specifically deuterated at the benzylic position. It was thus assumed that the impurities had little effect on the outcome of the reactions. The chemical yields (after exclusion of the initial impurities) ranged from 60 to $92 \%$. The chemical yields of substrates bearing deuterium on the silicon were in general 5-20\% less than the yields of the corresponding nondeuterated species. The origins of this difference in yields are not understood by us. The ${ }^{1} \mathrm{H}$ NMR spectra of the nondeuterated hydrosilation products are given in the previous paper. ${ }^{3}$ The proton-decoupled ${ }^{2} \mathrm{H}$ NMR data of the compounds 12, 28, and 35 are as follows. 12: ${ }^{2} \mathrm{H}$ NMR $\left(46.1 \mathrm{MHz},\left(\mathrm{CH}_{3}\right) \mathrm{CO}\right) \delta 0.85(\mathrm{~s}, 40 \%), 1.45$ (s, 15\%), $2.29(\mathrm{~s}, 40 \%), 4.20(\mathrm{~s}, 5 \%) .28:{ }^{2} \mathrm{H}$ NMR $(76.8 \mathrm{MHz}$, $\left.\left(\mathrm{CH}_{3}\right)_{2} \mathrm{CO}\right) \delta 2.20(\mathrm{~s}, 90 \%) 4.10(\mathrm{~s}, 10 \%)$. 35: ${ }^{2} \mathrm{H}$ NMR $(76.8 \mathrm{MHz}$, $\left.\left(\mathrm{CH}_{3}\right)_{2} \mathrm{CO}\right) \delta 2.29(\mathrm{~s}, 100 \%)$.

Acknowledgment. This work was supported by grants from the National Institutes of Health. 